\title{
Do teachers believe they are competent to promote healthy ICT use among their students?
}

\author{
R. Zlamanski ${ }^{\mathrm{a}, \mathrm{b}}$ and M. Ciccarelli, ${ }^{\mathrm{a}, \mathrm{b} *}$ \\ ${ }^{a}$ Centre for Research into Disability and Society, School of Occupational Therapy and Social Work, \\ Curtin University, Perth, Australia \\ ${ }^{\mathrm{b}}$ Curtin Health Innovation Research Institute, Perth, Australia
}

\begin{abstract}
Background: Information and communication technologies (ICT), including computers, are becoming commonplace tools for learning by school children in Australia and around the world. Teachers are responsible for integrating ICT into the school learning environment; however, they may not recognize how and when ICT use may compromise their students' physical health. Children's exposure to physical harm through the unhealthy use of ICT may have liability implications for the education sector. Objectives: To determine (i) whether teachers consider it their responsibility to promote healthy ICT use among their students; (ii) teachers' self-perceived competence to do so; and (iii) what teachers perceive are the barriers and enablers to promoting healthy ICT use among their students. Method: An online survey was developed for the study. All Catholic Education school principals in Western Australia $(n=157)$ were sent an email link to the survey for distribution to teachers at their respective schools. Over the three week survey period, 95 teachers completed the survey. Descriptive and inferential statistics were used to analyze the data and summarize participants' responses. Results: Fifty-five percent of teachers agreed they were concerned about their students' physical health when using ICT. Only 19\% of teachers reported they frequently or always provided their students with information on how to use computers in their class in a way, so as to promote physical health. Teachers identified barriers to promoting healthy computing use among students including; insufficient time (47\%), non-adjustable furniture (46\%), and insufficient knowledge (41\%). Male teachers reported more confidence in their ability to promote healthy ICT use among students than female teachers. Conclusion: Just over half of the teachers in this study were concerned for the physical health of their students when using ICT in the classroom. Respondents identified barriers that limit their ability to promote healthy practices to their students. Designing and implementing school-based computer ergonomics education programmes may assist teachers fulfil their duty of care in regard to the physical health and well-being of their students.
\end{abstract}

Keywords: ICT, ergonomics, school children, teacher education

\section{Introduction}

Information and Communication Technology (ICT) refers to equipment which produces, stores, and communicates information. Electronic ICT, such as computers and mobile phones has rapidly increased in availability over the last two decades and children have embraced this media. This global trend is reflected in the Australian Bureau of Statistics 2009 report that reported $79 \%$ of children accessed the internet, an increase of $14 \%$ in three years [2].
The report also included a new category for children's ownership of mobile phones.

The proliferation of ICT for leisure, social interaction, education and work requires that children be competent in using a variety of ICT. To facilitate this goal, the United Nations Education, Scientific and Cultural Organisation (UNESCO) aims to ensure all nations are able to educate their students with the best resources available. Education ministries throughout the world have adopted this aim and actively promote

\footnotetext{
${ }^{*}$ Corresponding author. E-mail: m.ciccarelli@curtin.edu.au
} 
the integration of ICT within schools as a learning resource for their students [20].

As a result of international and national policy, it is incumbent upon teachers to incorporate ICT use within the school's curricula. Exposure to ICT is a fundamental part of children's education from a young age [18]. Computer use has been associated with the development of musculoskeletal disorders (MSD) in adults. As children's exposure to ICT is similar to or greater than that of adults [4-5], there are implications that children's increased use of ICT may place them at risk of future MSD $[11,16]$. Computer Vision Syndrome is another health implication associated with children's increased use of computers [24].

Teachers are ideally placed to educate children in the safe use of ICT equipment. Schools also have a duty of care to take reasonable steps to ensure children are not exposed to harm in the course of their learning activities. Whether or not teachers are competent to do so is unknown. Competence is defined as the use of attitudes, skills and knowledge to perform an activity [8]. Professional development literature suggests that to improve competence one needs to increase knowledge; understanding of how that knowledge can be applied; skill in applying it; and the attitude to apply it correctly [15].

This study's objectives were to determine i) whether teachers consider they have a responsibility to promote healthy ICT use among their students; ii) teachers' perceptions regarding their competence to do so; and c) what teachers' perceive are the barriers and enablers to them promoting healthy ICT use among their students.

\section{Methods}

A cross-sectional descriptive study was conducted using an online survey. The survey questions were designed to address the research questions and gather population demographics.

\subsection{Participants and sampling method}

Western Australian primary and secondary school teachers currently employed in the Catholic Education system were invited to participate in this study. All Catholic school principals in Western Australia $(n=157)$ were sent an email link to the online survey inviting them to distribute the email to all teachers within their school.

\subsection{Materials}

An online survey was developed specifically for this study. The measure consisted of 37 questions in the following categories: (i) the ICT resources available in the school, including where, how and the purpose for which it is used; (ii) awareness and training in psychological health related to computer use; (iii) awareness and training in physical health related to computer use; (iv) attitudes toward computer-related ergonomics; (v) barriers and supports to the promotion of computer-related ergonomics to students; and, (vi) demographic data.

The online survey was piloted by four teachers employed in Western Australian non-government schools other than Catholic Education Office of Western Australia (CEOWA). Their feedback was incorporated into the final survey that was uploaded to, and administered via, Survey Monkey ${ }^{\circledR}$.

\subsection{Data analyses}

Descriptive (frequency count) and inferential (Chisquared) analyses were conducted using Predictive Analytical SoftWare (PASW v.18; SPSS Inc., 2009).

\section{Results}

\subsection{Number and demographics of participants}

Ninety-five teachers participated in the online survey. Twenty-eight percent were male and $72 \%$ were female. Forty-six percent of teachers were aged between 40 and 64 years. Nearly half of all respondents (49.5\%) had been teaching in schools for more than 10 years. Sixty-eight percent of teachers had permanent status and $65 \%$ were employed on a full-time basis. Most respondents $(n=35)$ reported their primary role was teaching students in Years 10 to 12 .

\subsection{Perceived responsibility promoting healthy computing among students}

Teachers identified a range of digital technologies available within their schools for student use. Table 1 shows the percentage of respondents who reported the technologies were available, were used in class and were easily accessible when needed. Over $90 \%$ of survey respondents reported desktop or laptop computers, email and internet access were available within their schools. 
Table 1.

ICT available and used in schools

\begin{tabular}{llll}
\hline ICT & $\begin{array}{l}\text { Availability } \\
(\%)\end{array}$ & $\begin{array}{l}\text { Usage } \\
(\%)\end{array}$ & $\begin{array}{l}\text { Easily } \\
\text { Accessible } \\
(\%)\end{array}$ \\
\hline Email & 94.7 & 92.6 & 92.6 \\
$\begin{array}{l}\text { Internet } \\
\text { Desktop or laptop } \\
\text { computer }\end{array}$ & 94.7 & 92.6 & 91.6 \\
$\begin{array}{l}\text { Printer } \\
\text { Digital camera }\end{array}$ & 93.7 & 91.6 & 89.5 \\
$\begin{array}{l}\text { Interactive } \\
\text { whiteboard }\end{array}$ & 84.2 & 91.6 & 82.1 \\
Digital projector & 81.1 & 60.0 & 58.9 \\
\hline
\end{tabular}

Thirty percent of teachers required their students to use computers on a daily basis. An additional $23 \%$ reported students used computers in their class between two and four times per week. Survey results are presented in Table 2 .

Table 2.

Frequency of computer use at school

\begin{tabular}{lc}
\hline Frequency & Number (\%) \\
\hline Daily & $29(30.5)$ \\
$2-4$ times per week & $22(23.2)$ \\
Weekly & $14(14.7)$ \\
Fortnightly & $9(9.5)$ \\
Monthly & $8(8.4)$ \\
Once per term & $3(3.2)$ \\
Less than once per term & $4(4.2)$ \\
\hline
\end{tabular}

Teachers required students to complete tasks such as research on the internet $(86 \%)$, preparing Word documents $(74 \%)$ and PowerPoint presentations $(68 \%)$. The variety and frequency with which teachers require their students to perform tasks using ICT equipment are presented in Table 3.
Table 3.

School activities requiring computer use

\begin{tabular}{ll}
\hline Task & Number (\%) \\
\hline Research on the internet & $82(86.3)$ \\
Word documents & $71(74.7)$ \\
PowerPoint presentations & $65(68.4)$ \\
Online worksheets & $45(47.4)$ \\
Digital editing (music, images) & $25(26.3)$ \\
Writing on blog, wiki, & $18(18.9)$ \\
discussion board & $8(8.4)$ \\
Game design &
\end{tabular}

Over $92 \%$ of teachers reported that they allocated homework which required students to work on a computer at home. Detailed frequencies are listed in Table 4 . Over $46 \%$ of teachers required students to use a computer for their homework at least once per week.

Table 4.

Frequency of computer use for homework

\begin{tabular}{|c|c|}
\hline Frequency & Number (\%) \\
\hline Daily & $6(6.3)$ \\
\hline $2-4$ times per week & $16(16.8)$ \\
\hline Weekly & $22(23.2)$ \\
\hline Fortnightly & $12(12.6)$ \\
\hline Monthly & $7 \quad(7.4)$ \\
\hline Once per term & $5 \quad(5.3)$ \\
\hline Less than once per term & $20(21.1)$ \\
\hline
\end{tabular}

Despite teacher expectations that their students will use digital technologies to complete schoolrelated work, only $80 \%$ of teachers agreed they had a professional responsibility to promote healthy computing practices to their students.

\subsection{Prior teacher training in computer ergonomics}

Eighty-two teachers responded to the question 'Have you received information or training in computer ergonomics to promote the physical health of students accessing and using computers'. Sixty-five percent of respondents reported they had not received any training.

Eighty percent of teachers agreed they had a responsibility to promote healthy computing practices among their students, only $21 \%$ reported undertaking any form of training in computer ergonomics. Of those who had received training, more than half re- 
ported it was more than 12 months ago for less than one hour.

Sources of training reported by teachers included professional development workshop $(n=13)$, ICT specialist $(n=7)$, work colleagues $(n=6)$, health professional $(n=4)$, university $(n=3)$.

\subsection{Perceived confidence and competence}

Based on the premise that achieving competence requires the necessary attitudes, skill and knowledge, the following results were obtained from survey respondents.

Fig. 1 illustrates the percentage of teachers' who agreed they had the necessary skills and knowledge about computer-related ergonomics and were confident to teach others. In relation to teachers' satisfaction with their knowledge of computer-related ergonomics, 34\% reported they were satisfied with their knowledge.

Forty-seven percent of teachers agreed they were confident in their ability to promote healthy computing to their students. Only $18 \%$ of teachers reported they believed they had the skills to train others about computer ergonomics.

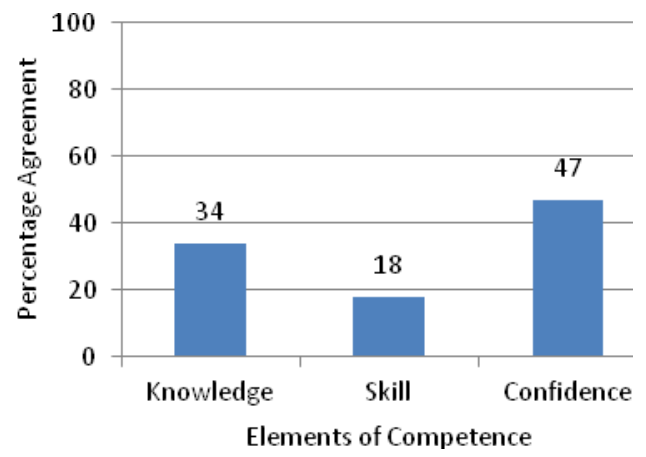

Figure 1. Teachers' perceived skills, knowledge and confidence to teach others healthy computing

Individual elements of knowledge, skill and confidence were cross tabulated against demographic data. Male teachers rated themselves more highly across each category compared to female teachers. With regard to knowledge of computer-ergonomics, $57 \%$ of males believed they had sufficient knowledge compared to $32 \%$ of female respondents. Forty-seven percent of males believed they had sufficient skills in computer-related ergonomics compared to $11 \%$ of females; and $76 \%$ of male teachers were confident in their ability to teach others about healthy computing compared to $49 \%$ of females. Combining each element into one variable named 'Competence' and cross tabulating against demographic data identified a statistically significant difference between gender. Overall perceived competence to promote healthy computing among others was reported by $33 \%$ of males and $6 \%$ of females $(\mathrm{p}=0.002)$.

The frequency with which teachers reminded or provided information to their students about ways to promote their physical health during ICT use is shown in Table 5.

Table 5. Frequency that teachers promote healthy computing to students

\begin{tabular}{lc}
\hline Frequency & Number $(\%)$ \\
\hline Every time & $4(4.2)$ \\
Frequently & $14(14.7)$ \\
Sometimes & $35(36.8)$ \\
Never & $25(26.3)$ \\
\hline
\end{tabular}

\subsection{Barriers and enablers}

Fig. 2 illustrates the barriers that teachers believed limited their ability to promote healthy computing among students. These include insufficient knowledge (reported by $41.1 \%$ of respondents), insufficient time during class to spend on students' adjusting their workstations $(47.4 \%)$, lack of adjustable furniture $(46.3 \%)$, and their own lack of confidence $(10.5 \%)$. Teachers' qualitative responses to open ended questions about barriers also identified lack of funding for resources such as appropriate furniture or ergonomic equipment, and students having to share computers in the classroom or the school's computer laboratory.

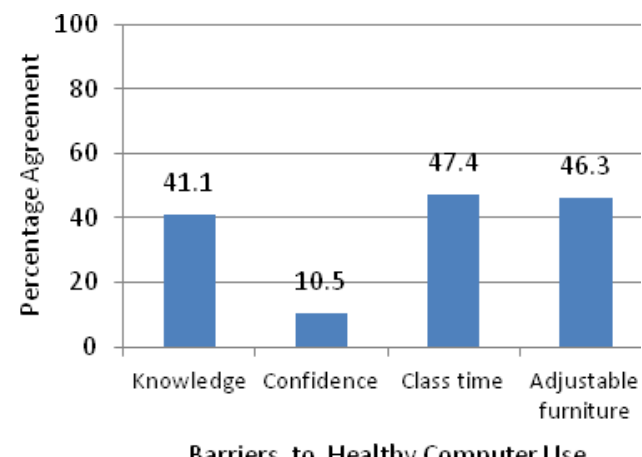

Barriers to Healthy Computer Use 
Figure 2. Perceived barriers to promoting healthy computing

With regard to factors that enabled or supported teachers to promote healthy computing to students, $64 \%$ of teachers agreed the use of ICT is encouraged as a student learning resource at their school; however, most teachers believed currently their school culture and practices did not encourage staff or students to use computers in a physically healthy way.

\section{Discussion}

\subsection{Summary}

Learning and adopting healthy behaviours from a young age increases the likelihood of those behaviours becoming part of an overall lifestyle [1, 5, 8]. The World Health Organisation (1997) acknowledges that schools are an effective place to undertake health promotion [22]. Teachers are, therefore, ideally placed to influence children's computing behaviours [5]. Unlike the widely recognized occupational health and safety regulations that provide guidelines to employers about minimizing hazards for adult workers using ICT in occupational settings, there is little legislative protection, beyond expectations of the school's general duty of care of children when they are at school, in place for children who are required to use ICT during their learning activities.

Despite a majority of teachers in this study reporting they did not have sufficient knowledge or skills about computer ergonomics, nor had they received formal training or professional development in this area, almost half the respondents reported they were confident in their ability to do so. This mismatch between knowledge and skills, and perceived competence is a concern because providing inaccurate information to students about healthy ways to use their computers may be no better than providing no information.

Similar findings are reflected in prior research by Dockrell et al. [6]. Their survey of teachers in the Republic of Ireland showed $99.7 \%$ of schools had computers, $89.6 \%$ of teachers received computer training but only $17.6 \%$ of teachers received training in computer ergonomics. In addition, $90.6 \%$ of teachers felt they needed more information regarding training in computer ergonomics. Studies conducted in New Zealand [11] and Japan [16] also reported teachers were dissatisfied with their knowledge of computer ergonomics. These studies also found res- pondents had some awareness of risks associated with computer use but this knowledge was not incorporated into students' computer education $[11,16]$.

\subsection{Perceived competence among male and female teachers}

This study has found gender may be a predictive factor with respect to a teacher's competence to promote healthy computer use to their students, with males more likely to have higher levels of competence than females. Similar results have been found in previous studies which have considered teachers' competence in relation to general ICT use and integration of ICT by teachers within schools. A study study of 1,058 adults noted that, even with an equivalent level of computer experience, females reported higher levels of anxiety when using ICT than males [3]. A 2006 study of 1,500 teachers undertaken by the Western Australian Department of Education and Training found higher levels of ICT competence were likely to be found in men, younger teachers, less experienced teachers, and secondary school teachers [20].

\subsection{Barriers and enablers}

Having insufficient time in class and lack of adjustable furniture were the main barriers to promoting healthy computing identified by the study sample. Students who move from one class location to another typically use generic 'hot desks' used by all other students when scheduled in that class. This holds true for computer workstations within individual classrooms or the school's computer laboratory. Furniture that does not match the wide variation in the anthropometric needs of school children has been widely discussed in the ergonomics literature over the past two decades $[21,13]$, with few improvements to address this concern being evident.

Teachers also acknowledged limitations in their own knowledge about computer ergonomics, which when coupled with the challenges posed by a mismatched physical environment, not surprisingly has resulted in less than twenty per cent of respondents taking steps to promote healthy computing always or frequently.

While some teachers reported support from their line managers or school administrators to learn more about implementing healthy ways of using ICT, the majority reported little support or understanding at an administrative level within the education sector. 
Inadequate physical environments in the classroom to support students using computers, limited understanding by teachers of the potential health risks and strategies, and an apparent apathy by school administrators to addressing the physical health issues associated with ICT use by students, suggest a macroergonomics approach as previously described by Legg and Jacobs [12] is necessary.

\subsection{Implications for the education sector}

Teachers in the target population for this study are required to integrate ICT within the learning environment as mandated by the Western Australian Curriculum Council's Curriculum Framework to facilitate students' ability to "select, use and adapt technologies to meet their needs" (p.22) [9]. Schools and teachers have a duty of care for the health and wellbeing of their students when at school. Teachers in this study reported a greater awareness of the need to protect students' psychological well-being when using a computer. Given the global attention and effort which has been made to counter cyber-bullying on protecting students from online pornography and sexual predators, this finding was expected. However, the sample surveyed reported having insufficient skill and knowledge in computer ergonomics to promote using ICT in a physically healthy way.

During the 12 month period between 2010 and 2011 in which this study was conducted, anecdotally, the increase in portable technologies into the classroom has been exponential. The introduction of tablet technologies and software 'apps', has provided affordable and portable e-learning resources for schools. However, these new smaller and more portable digital technologies also provide a range of new potential risks to children's physical health. The impact on postures and associated muscle activity while using the tablets is yet to be fully determined.

Expecting students to use ICT and potentially exposing them to physical harm may have liability implications for the education sector. To minimize physical health risks associated with students' use of ICT, the following strategies have been recommended: (i) include computer-ergonomics education in pre-service education curricula for trainee teachers [12]; (ii) provide opportunities for school-based professional development in healthy computing for teachers; (iii) encourage schools to work collaboratively with ergonomists in the selection of school furniture and equipment, and classroom design and layout; (iv) develop a culture within the education sector where steps taken to promote healthy computing are considered as important in daily classroom routine as other health promotion strategies including the embedding of school ICT policies for cyber safety, and the widely accepted sun-safe policy and practice of 'No hat, no play' among Australian schools [8].

\subsection{Study limitations}

The small sample size $(n=95)$ is not sufficient to generalize results to the target population; however, findings are consistent with earlier studies. Although teachers were familiar with the online survey tool and it provided access to teachers throughout Western Australia, overexposure to online surveys may account for teachers' low rate of participation. Distribution of the survey to teachers by school administrators is unknown. Contact with school administrators prior to issuing the survey to encourage their support may have resulted in higher participation rates. Future studies using a mixed-methods design incorporating the use of focus groups may improve participation rates.

\section{Conclusion}

Schools encourage their students to use ICT for learning but are potentially placing students at risk of physical harm. Teachers' acknowledge they have a responsibility to promote healthy use of ICT among their students yet they overestimate their confidence in their ability to do so, as few have the skills or training to provide effective education in computer ergonomics to their students.

The implementation of a macro-ergonomics approach within school curricula may promote an increase in overall competence among teachers and subsequently among students in order to minimize physical and visual health risks during ICT use in the classroom. There is growing support for this approach within the ergonomics community [12]; however challenges remain in how ergonomics education can be introduced into the tertiary education curricula of pre-service teachers and within the culture of the education sector. The small number of respondents to this survey (out of a target population of 4,000 teachers employed in Catholic Education schools in Western Australia) may be indicative of the lack of concern the education sector has about any health related aspects of digital learning technologies. 
It is likely e-learning resources will continue to be an important element in the classroom and the importance and relevance of an ergonomics approach to ensure healthy use of this technology among children is evident.

\section{References}

[1] L. Alexander and C. Currie, Young people's computer use: implications for health education, Health Education 104 (2004), 254-261.

[2] Australian Bureau of Statistics, 4901.0 - Children's participation in cultural and leisure activities, (2009), Canberra

[3] A. Broos, Gender and information and communication technologies (ICT) anxiety: Male self-assurance and female hesitation, Cyber Psychology \& Behavior 8 (2005), 21-31.

[4] M.Ciccarelli, L. Straker, S. Mathiassen and C.Pollock, ITKids Part I : Children's occupations and use of information and communication technologies, Work 38 (2011), 401-412.

[5] M.Ciccarelli, L. Straker, S. Mathiassen and C.Pollock, ITKids Part II : Variation of postures and muscle activity in children using different information and communication technologies, Work 38 (2011), 413-427.

[6] S. Dockrell, E. Fallon, M. Kelly and R. Galvin, Sources and nature of secondary school teachers' education in computerrelated ergonomics, Computers \& Education 53 (2009), 504510.

[7] S. Dockrell, E. Fallon, M. Kelly, B. Masterson, and N. Shields, School children's use of computers and teachers' education in computer ergonomics, Ergonomics 50 (2007), 1657-1667.

[8] M. Fleming and E. Parker, Health promotion: Principles and practice in the Australian context (3rd ed.) Allen \& Unwin Sydney, Australi, 2007.

[9] B. Giles-Corti, D. English, C. Costa, E. Milne, D. Cross and R. Johnston, Creating SunSmart schools, Health Education Research 19 (2004), 98-109.

[10] Government of Western Australia Curriculum Council, Curriculum framework for kindergarten to year 12 education in Western Australia (1998), http://www.curriculum.wa.edu.au.

[11]K. Jacobs and N. Baker, The association between children's computer use and musculoskeletal discomfort, Work 18 (2002), 221-226.

[12]K. W. Lai, Health risks with teachers' computer use: Some New Zealand observations, Journal of Information Technology for Teacher Education 9 (2000), 303-318.

[13] S.J. Legg and K. Jacobs, Ergonomics for schools, Work 31 (2008), 489-493.

[14] G. Panagiotopoulou, K. Christoulas, A. Papanckolaou and K. Mandroukas, Classroom furniture dimensions and anthropometric measures in primary school, Applied Ergonomics 35 (2004), 121-128.

[15] Professional Development Partnership, Competence, http://www.pd-how2.org/2 9.htm

[16]L.B. Royster, A healthy approach to classroom computers Preventing a generation of students from developing repetitive strain injuries, North Carolina Law Review 80 (2002), 275314.

[17] M. Sotoyama, U. Bergqvist, H. Jonai and S. Saito, An ergonomic questionnaire survey on the use of computers in schools, Industrial Health 40 (2002), 135-141.
[18]L.M. Straker and C.M. Pollock, Optimizing the interaction of children with information and communication technologies, Ergonomics 48 (2005), 506-521.

[19] L.M. Straker, C.M. Pollock and B. Maslen, Principles for the wise use of computers by children, Ergonomics 52 (2009), 1386-1401.

[20]United Nations Educational, Scientific and Cultural Organization, Information and communication technology in education: A curriculum for schools and programme of teacher development, (2002), http://unesdoc.unesco.org/images/0012/001295/129538e.pdf.

[21] Western Australian Government Department of Education and Training. Teacher ICT skills. (2006), http://www.det.wa.edu.au/education/accountability/docs/ict report final.pdf.

[22] J. Wilson, Computer laboratory workstation dimensions: Scaling down for elementary school children, Computers in the Schools 8 (1991), 41-48.

[23] World Health Organization. Health promotion glossary (1997), http://www.who.int/hpr/NPH/docs/hp_glossary_en.pdf.

[24]Z. Yan, L. Hu, H. Chen and F. Lu, Computer vision syndrome: A widely spreading but largely unknown epidemic among computer users, Computers in Human Behavior 24 (2008), 2026-2042. 